\title{
LA FINANCIACIÓN DE LAS DESTINATION MANAGEMENT ORGANIZATIONS EN LOS PRINCIPALES DESTINOS DEL MUNDO. UN ANÁLISIS DESDE LA PERCEPCIÓN DE SUS GESTORES
}

\author{
Isabel Carrillo-Hidalgo* \\ Universidad de Jaén \\ https://orcid.org/0000-0002-0914-5084 \\ Juan Ignacio Pulido-Fernández* \\ Universidad de Jaén \\ https://orcid.org/0000-0002-9019-726X
}

\section{RESUMEN}

En la actualidad, una de las fórmulas de gestión de destinos consideradas como más adecuadas para garantizar el desarrollo sostenible y competitivo del turismo son las DMO público-privadas. Sin embargo, la gestión del turismo a través de DMO público-privadas no es una cuestión extendida, ni siquiera en las ciudades más visitadas del mundo.

Este tipo de entidades debe caracterizarse por una menor dependencia del sector público a nivel organizativo, presupuestario y de toma de decisiones, considerándose como una alternativa para dar solución al problema de financiación al que se enfrenta la gestión de los destinos.

Por ello, resulta interesante conocer cómo se financian las DMO de algunas de las ciudades más visitadas del mundo, valorando así su idoneidad de acuerdo con lo establecido por la literatura científica. Así como tratar de entender la razón de su comportamiento, estudiando si tienen asumidas las ventajas e inconvenientes de las diferentes fuentes de financiación.

Palabras clave: Destination Management Organization; gestión de destinos; estructura financiera; principales destinos del mundo; análisis de percepción.

The financing of destination management organizations in the main destinations of the world. An analysis from the perception of their managers

Fecha de recepción: 2 de octubre de 2019

Fecha de aceptación: 5 de marzo de 2020

* Laboratorio de Análisis e Innovación Turística (LAInnTUR). Universidad de Jaén. Paraje las Lagunillas s/n.23071 JAÉN (España).E-mail: ihidalgo@ujaen.es, jipulido@ujaen.es 


\begin{abstract}
Currently, one of the management destinations formulas considered as the most adequate to guarantee the sustainable and competitive development of tourism are public-private DMO. However, tourism management through public-private DMO is not a widespread issue, even in all the most visited cities in the world.

This type of entities must be characterized by a lower dependence on the public sector at an organizational, budgetary and decision-making level, being considered as an alternative to solve the financing problem faced by destination management.

Therefore, it is interesting to know how the DMO of the most visited cities in the world are financed, thus assessing their suitability according to what is established by the scientific literature. As well as trying to understand the reason of their behavior, studying whether they have assumed the advantages and disadvantages of different sources of funding.
\end{abstract}

Keywords: Destination Management Organization; destination management; financial structure; main destinations of the world; perception analysis.

\title{
1. INTRODUCCIÓN
}

El turismo es un fenómeno social que cada vez tiene una mayor presencia y expansión internacional. De hecho, las cifras de llegadas de turistas internacionales no paran de crecer, aumentando en un $7 \%$ en 2017 (UNWTO, 2018) y con una previsión de que la tendencia se mantendrá en 2018.

Además, se trata de una actividad que afecta, y se ve afectada, por los intereses de múltiples actores que deben entenderse, respetarse y coordinarse entre ellos. Por ello su gestión requiere de una entidad capaz de adaptar la oferta turística de los destinos a las necesidades del mercado y de consolidar un turismo competitivo, sostenible y de calidad.

Esta gestión de un destino turístico conlleva dos funciones principales: debe buscar la mejora del bienestar social y económico de los residentes del destino y debe ofrecer una actividades y experiencias que satisfagan las necesidades y expectativas de los turistas (Bornhorst et al., 2010).

En la actualidad, los principales destinos turísticos (Barcelona, Ámsterdam, Londres, Berlín, Nueva York, Toronto, Miami, Los Ángeles, etc.) están apostando por la gestión turística a través de una Destination Managent Organization (en adelante, DMO) (Muñoz y Fuentes, 2013), considerada como el mayor nivel de formalización existente en el ámbito de las relaciones público-privadas y la conformación de redes para la promoción de un destino turístico.

Según la UNWTO (2004) una DMO es una organización responsable de la gestión y marketing del destino que, en general, puede operar a nivel nacional, regional y local. Por tanto, es fundamental que esta entidad desempeñe funciones de "marketing de destino externo" y de "desarrollo de destino interno" (Presenza et al., 2005), llegando a considerarse una de las mejores fórmulas de gestión de destinos para garantizar el desarrollo sostenible y competitivo del turismo (Carrillo-Hidalgo y Pulido-Fernández, 2019). 
Es muy usual confundir los conceptos de Destination Marketing Organization con DMO, llegando a emplearse indistintamente ambos conceptos (Sheehan et al., 2007). Es cierto que, en el pasado, las funciones de una DMO se centraban en actividades de marketing y estas son, a día de hoy, uno de los roles más importantes de las DMOs (Arbogast et al., 2017). Sin embargo, en la actualidad, hay una marea académica creciente que aboga por que las DMO incluyan competencias enmarcadas dentro de la gestión del destino (Sheehan et al., 2016).

Por tanto, una DMO debe ser capaz de gestionar y promocionar los recursos de un destino, debiendo comportarse como un órgano de gobierno bajo una autosuficiencia financiera garantizada (ETB y TMI, 2003), siendo una de las formas organizativas más adaptada a la diversificación y autonomía financiera en la gestión de un destino (Das y Ghosh, 2014). Sin embargo, no existe una estructura financiera determinada para las entidades de gestión turística, todo depende de su forma jurídica, del tipo de actividades que desarrollen, etc.

Pese a que la literatura científica apenas establece cómo deben financiarse las DMO (Reinhold et al., 2019), sí tiene asociadas una serie de ventajas y desventajas al origen de los recursos financieros de las entidades de gestión turística, que establecen unas premisas mínimas a tener en cuenta a la hora de determinar la estructura financiera de estas entidades y que se analizan en el apartado 2.2.del marco teórico (DMAI, 2015; ETB y TMI, 2003; FEMP, 2008; Ramió, 2009; Ruiz, 2010; UNWTO, 2008).

Esta investigación parte de la hipótesis de que las DMO de las ciudades con más éxito en materia de turismo a nivel mundial no mantienen una estructura financiera acorde con las características de los destinos y que podría ser más eficaz y eficiente si asumieran cuáles son las verdaderas ventajas e inconvenientes de las diferentes fuentes de financiación.

El objetivo principal es conocer la opinión de las DMO con los atributos e inconvenientes asociados a las diferentes fuentes de financiación y su coherencia con la estructura presupuestaria de estas.

Para ello, se ha realizado un cuestionario a las catorce DMO de las treinta y cinco ciudades más visitadas del mundo, que ha sido respondido por altos cargos de estas organizaciones, sobre la estructura financiera de la entidad. La información obtenida, complementada con un análisis de fuentes secundarias, permite alcanzar unas conclusiones basadas en los resultados arrojados por el análisis de esta información.

\section{MARCO TEÓRICO}

\subsection{Destination Management Organization}

El carácter cambiante, complejo, global y sistémico del turismo y la cantidad de agentes cuyos intereses y objetivos afectan y se ven afectados por la actividad turística en un destino hacen necesario la existencia de una entidad que se encargue de gestionar esta actividad, de manera que se logre un aumento de la competitividad y el desarrollo sostenible del turismo.

Desde la perspectiva de la oferta, el turismo, como actividad, se caracteriza por dos adjetivos que lo diferencian de otros sectores: transversalidad y territorialidad (Knafou, 
1991; Pulido-Fernández, 2010). Además de ser una actividad fundamentalmente privada, en la que la prestación y explotación de actividades y servicios turísticos la desarrolla, por lo general, el sector privado, mientras la Administración debe garantizar un correcto funcionamiento del sector (Galván, 2014).

Dadas estas características que definen a la actividad turística, es necesario que algún tipo de organización o entidad coordine los diferentes eslabones de la cadena de producción, promoción y comercialización del producto turístico.

El tipo de gestión que se lleve a cabo permitirá, o no, alcanzar el objetivo de toda política turística: ofrecer una experiencia turística de calidad, maximizando los beneficios de las diferentes partes interesadas y salvaguardando la integridad social, cultural y medioambiental del territorio (Kerimoğlu y Çiraci, 2008).

Según Manente (2008:3), "la gestión de los destinos turísticos implica administrar y apoyar la integración de diferentes recursos, actividades y agentes involucrados a través de políticas y medidas apropiadas. Lleva consigo competencias gubernamentales en materia de toma de decisiones y en materia de planificación, organización y control de actividades empresariales, que deberían incumbir al sector público".

Existen multitud de definiciones sobre qué es una DMO, que tratan de facilitar la comprensión de su naturaleza, sus funciones y las actividades que realiza. La literatura científica ha definido la DMO como el actor que debe actuar como un órgano de gobierno encargado de planificar, gestionar y organizar los recursos diversos y variados de un destino (Pike, 2004; Presenza et al., 2005).

Las DMO son agentes que actúan como intermediarios entre el entorno competitivo externo y el entorno interno del destino. En el entorno competitivo externo, el objetivo de la DMO es la recopilación de conocimiento y el posicionamiento competitivo del destino en el mercado. En el entorno interno, el objetivo es divulgar este conocimiento y la colaboración de las partes interesadas (Sheehan et al., 2016).

Existen diferentes modelos de gestión de destinos turísticos y no hay una fórmula única, lo ideal es que el modelo se adapte a las condiciones particulares de cada destino.

La estructura jurídica de la entidad encargada de la gestión del turismo en un destino es fundamental. Esta estructura ha ido evolucionando en función de la participación del sector público y privado, de manera que cada vez, en mayor medida, los destinos optan por la creación de entidades de gestión de carácter mixto (Arcarons et al., 2010; FEMP, 2008; Izard et al., 2010; Pulido-Fernández, 2014), donde se enmarcan las DMOs.

La forma jurídica, la estructura organizativa, el tipo de actividad que desarrollen o sus preferencias en materia de financiación, entre otras, determinarán la estructura financiera de las entidades de gestión turística.

La colaboración público-privada es fundamental para la consecución de unos objetivos que logren mejorar la competitividad del destino. En el ámbito de la financiación de las entidades, esta colaboración se extrapola a la necesidad de una corresponsabilidad financiera.

Siguiendo la clasificación desarrollada por FEMP (2008) y DMAI (2015), el origen de las fuentes de financiación de las entidades de gestión turística y sus principales características quedan resumidas en el Cuadro 1. 


\section{Cuadro 1 \\ FUENTES DE FINANCIACIÓN DE LAS ENTIDADES DE GESTIÓN TURÍSTICA}

\begin{tabular}{|c|c|c|}
\hline & ORIGEN & CARACTERÍSTICAS \\
\hline $\begin{array}{l}\text { Financiación } \\
\text { Pública }\end{array}$ & $\begin{array}{l}\text { 1. Transferencias/aportaciones de } \\
\text { otros niveles de la Administración } \\
\text { (supranacional, estatal, comunidad } \\
\text { autónoma, región, etc.). } \\
\text { 2. Aportaciones directas presupuesto } \\
\text { ordinario de las corporaciones locales. } \\
\text { 3. Donación de productos y servicios } \\
\text { públicos. }\end{array}$ & $\begin{array}{l}\text { - Se recomienda que la mayor } \\
\text { parte del presupuesto sea de } \\
\text { origen público en las entidades } \\
\text { de gestión turística de destinos } \\
\text { en fase inicial del desarrollo } \\
\text { turístico. } \\
\text { - Papel de liderazgo. } \\
\text { - Garantiza la viabilidad del ente. }\end{array}$ \\
\hline $\begin{array}{l}\text { Fin } \\
\text { priv }\end{array}$ & $\begin{array}{l}\text { 1. Cuotas de afiliación. } \\
\text { 2. Ingresos de asociaciones. } \\
\text { 3. Patrocinios. } \\
\text { 4. Aportaciones institucionales no públicas. } \\
\text { 5. Aportaciones voluntarias de turistas y/o } \\
\text { empresarios. }\end{array}$ & $\begin{array}{l}\text { - La financiación privada debe ser } \\
\text { proporcional a la masa crítica del } \\
\text { sector. } \\
\text { - Es una manera de compensar el } \\
\text { peso de la financiación pública. } \\
\text { - Suele predominar en entidades } \\
\text { de gestión muy focalizadas en } \\
\text { la promoción y el marketing del } \\
\text { destino. }\end{array}$ \\
\hline $\begin{array}{l}\text { Recursos } \\
\text { Autogenerados }\end{array}$ & $\begin{array}{l}\text { 1. Prestación de servicios o venta de } \\
\text { productos. } \\
\text { 2. Gestión de equipamientos públicos. } \\
\text { 3. Inversiones financieras. } \\
\text { 4. Publicidad. } \\
\text { 5. Merchandising. } \\
\text { 6. Central de reservas. } \\
\text { 7. Venta de productos y servicios. } \\
\text { 8. Publicaciones. } \\
\text { 9. Organización de convenciones/ } \\
\text { congresos. } \\
\text { El origen de los fondos es tanto de empresas } \\
\text { privadas como de los propios turistas } \\
\text { (Beritelli y Laesser, 2014). }\end{array}$ & $\begin{array}{l}\text { - Cada vez genera mayor interés } \\
\text { tanto por los entes de gestión de } \\
\text { destinos, como por la literatura } \\
\text { científica. } \\
\text { - Con la adecuada estrategia y } \\
\text { planificación, la entidad puede } \\
\text { asegurarse una importante } \\
\text { proporción de su presupuesto. } \\
\text { Este tipo de financiación, junto } \\
\text { con las diferentes opciones de } \\
\text { financiación privada, tiene mayor } \\
\text { aceptación por la población que } \\
\text { el establecimiento de tributos al } \\
\text { turismo (Rodríguez, 2009). }\end{array}$ \\
\hline
\end{tabular}

Fuente: Elaboración propia a partir de FEMP (2008) y DMAI (2015). 
Puede decirse que no existe un modelo común para determinar la estructura presupuestaria de una entidad de gestión turística. Todo depende de la situación del destino, influenciado por: la política local, la aceptación del turismo por la población residente, la fase del ciclo de vida de la actividad turística y madurez del sector, la importancia relativa del turismo con respecto a otras industrias, la trayectoria de la entidad y su estructura (Pike, 2007).

\subsection{Los problemas de financiación en la gestión de destinos}

Tanto los destinos, en general, como las DMO, en particular, se enfrentan a un problema en materia de financiación. Este problema parte de ese crecimiento constante del turismo, al que se ha hecho referencia con anterioridad que origina un crecimiento de la oferta que no va acompañado de una adecuada planificación de las inversiones necesarias, terminando por afectar a la sostenibilidad del destino y su competitividad.

Hay destinos que se encuentran en serios problemas presupuestarios, ya que su población de derecho, que asume la carga impositiva, es muy inferior a la de hecho (que incluye turistas y propietarios de segundas residencias) (Izard et al., 2010), llegando a considerarse el sistema de financiación local como insuficiente (Biedma, 2010; Bodlender, 1982; Fluvià et al., 2001; Hara, 2013; Pastor y Soler-Domingo, 2009; Román-Márquez, 2011; Rubio, 2002; Ruiz y Guía, 2004; Voltes-Dorta et al., 2014), soportando los propios ayuntamientos los sobrecostes por los servicios públicos extraordinarios que tienen que prestar a causa de su condición turística, sin recibir aportes financieros compensatorios.

El problema de la financiación se ve incrementado por la dependencia presupuestaria de las transferencias gubernamentales, las cuales son vulnerables al ciclo económico en que se encuentre, los recortes presupuestarios y el ciclo y signo político del gobierno.

Esta situación deriva en un déficit crónico, con una mayor tendencia al endeudamiento (Pastor y Soler-Domingo, 2009), en una mayor presión fiscal para la población residente o en una menor prestación de servicios públicos que, a su vez, lleva a la pérdida de competitividad por parte del destino.

Esta problemática financiera de la gestión de los destinos turísticos se ve acrecentada cuando los sistemas impositivos locales se caracterizan por la uniformidad y la falta de flexibilidad, de manera que los propios destinos tienen muy poco margen de maniobra en materia fiscal (Biedma, 2010; Fluvià et al., 2001).

Por tanto, el sistema de financiación debe atribuir los fondos de una forma proporcionada a la necesidad de gasto.

La literatura científica identifica diferentes formas de atajar esta problemática.

Ruiz y Guía (2004) consideran fundamental garantizar una mayor equidad en la distribución de los fondos que provienen de los presupuestos gubernamentales, siendo necesario establecer indicadores de la población real del destino. De este modo, es indispensable establecer un sistema regular que proporcione figuras financieras compensatorias al mayor esfuerzo financiero realizado por el destino.

Además del sistema regular señalado, también es interesante fijar mecanismos puntuales de compensación financiera entre la administración estatal, regional y el destino, de modo que se establezca una política de subvenciones que cubran determinadas competencias derivadas del carácter turístico del destino (Román-Márquez, 2011; Ruiz y Guía, 2004). 
Otra posibilidad, que plantea Biedma (2010), es establecer unos fondos de nivelación que compensen los desequilibrios en la distribución de la renta local de los destinos turísticos, materializados en fondos de cooperación regionales y de nivelación de servicios con una dotación presupuestaria que responda al papel que los destinos turísticos desempeñan.

De hecho, es muy importante que los destinos turísticos próximos aúnen esfuerzos entre ellos y que también exista colaboración entre estos y la región a la que pertenecen, de modo que determinados servicios se presten a través de consorcios de gestión de servicios de interés común (Ruiz y Guía, 2004). Para ello, existe la figura de los convenios entre administraciones (Biedma, 2010), con los que se pretende participar de la solución a los problemas de sobrecarga presupuestaria que arrastran los destinos turísticos. Sin embargo, la realidad ha demostrado la insuficiencia de los mismos.

En materia de fiscalidad local sobre el turismo (Ruiz, 2010), una buena opción es la mejora y flexibilización de los tributos ya existentes, o el establecimiento de algún tributo propio o tasa vinculado con la actividad turística, que dote de más medios y oportunidades a los gestores (Rodríguez, 2009; Ruiz y Guía, 2004).

Biedma (2010) valora la posibilidad de establecer un tributo turístico relacionado con el desarrollo del producto, que vincule el aumento de la necesidad de gasto con la actividad económica que genera el turismo, siendo el más común el "impuesto al alojamiento".

Otra opción en materia de fiscalidad local es aumentar el tipo impositivo del Impuesto sobre Bienes Inmuebles para las segundas residencias con fines turísticos, gravando estas últimas con un tipo superior (Biedma, 2010).

Crear DMO público-privadas se plantea como una solución al problema de la financiación, al diversificar los recursos financieros de los destinos turísticos con una participación más activa del sector privado y optando por los recursos autogenerados por la propia organización (Izard et al., 2010), dependiendo así en menos medida de las transferencias presupuestarias públicas.

Sin embargo, es necesario tener en cuenta las ventajas e inconvenientes de cada una de las fuentes de financiación, las cuales han sido identificadas por la literatura científica y quedan resumidas en la Cuadro 2.

Hristov y Zehrer (2019) reconocen que las DMO cuentan con limitaciones financieras dan lugar a enfrentan desafíos severos para la creación de valor para los destinos, turistas y las organizaciones miembros.

Por último, algunos autores barajan la posibilidad de que los destinos turísticos financien determinados proyectos a través de deuda, emitiendo bonos vinculados a los ingresos derivados del turismo, como es el caso de Orange County Florida Tourism Development Tax Refunding Revenue Bond (Hara, 2013).

No existe, por tanto, una solución única a la problemática financiera a la que se enfrentan los destinos turísticos. Todo depende de las circunstancias particulares de cada uno, del tipo de entidad encargada de la gestión del turismo, del entorno y contexto en que se mueve, de los agentes que participan de la gestión turística y los afectados por ésta, de su sistema tributario, de las relaciones que mantengan con otras administraciones, transversal y horizontalmente, así como del nivel de implicación del sector privado. 


\section{Cuadro 2 \\ VENTAJAS E INCONVENIENTES SEGÚN ORIGEN DE LA FINANCIACIÓN}

\begin{tabular}{|c|c|c|}
\hline & Ventajas & Inconvenientes \\
\hline $\begin{array}{l}\text { Financiación } \\
\text { pública }\end{array}$ & $\begin{array}{l}\text { V1: Facilita la implicación del sector } \\
\text { público en el desarrollo de la } \\
\text { política turística de su entorno. } \\
\text { V2: Favorece la transparencia en } \\
\text { cuanto al destino de los fondos, } \\
\text { al estar sujetos a las normas de } \\
\text { la contabilidad y transparencia } \\
\text { pública. } \\
\text { V3: Favorece la igualdad de todas } \\
\text { las empresas interesadas en } \\
\text { la participación en la gestión } \\
\text { turística. } \\
\text { V4: Asegura la estabilidad de la DMO a } \\
\text { medio-largo plazo. }\end{array}$ & $\begin{array}{l}\text { I1: Reduce la rapidez de respuesta de } \\
\text { las DMO a las necesidades del } \\
\text { mercado global, al entrar en juego la } \\
\text { normativa y burocracia pública. } \\
\text { I2: Las características propias de la } \\
\text { contabilidad pública no ayudan a } \\
\text { que el sector privado visualice la } \\
\text { asignación de los fondos a unos } \\
\text { objetivos medibles } \\
\text { I3: La asignación de fondos públicos a } \\
\text { un sector económico determinado } \\
\text { puede generar recelos en la } \\
\text { población. } \\
\text { I4: El sector privado entiende la } \\
\text { aportación pública como una } \\
\text { obligación derivada del pago de } \\
\text { impuestos, lo que no ayuda a que el } \\
\text { sector público y privado trabajen en } \\
\text { un mismo sentido. } \\
\text { I5: Favorece la dependencia del sector } \\
\text { público. } \\
\text { I6: Supone una mayor influencia de } \\
\text { los poderes públicos en la toma de } \\
\text { decisiones de la DMO. }\end{array}$ \\
\hline $\begin{array}{c}\text { Financiación } \\
\text { privada }\end{array}$ & $\begin{array}{l}\text { V1: Supone un estímulo paras las } \\
\text { DMO para controlar su gestión } \\
\text { y su eficacia en la consecución } \\
\text { de objetivos, para que el sector } \\
\text { privado esté dispuesto a participar. } \\
\text { V2: Permite la integración efectiva } \\
\text { entre sector público y privado. } \\
\text { V3: Favorece que sector público y } \\
\text { privado trabajen en la misma } \\
\text { dirección. } \\
\text { V4: Reduce la influencia de la política } \\
\text { en la gestión de la DMO. } \\
\text { V5: Reduce la influencia de la política } \\
\text { en la gestión del destino. } \\
\text { V6: Reduce la dependencia de fondos } \\
\text { públicos de la DMO. } \\
\text { V7: Favorece la coordinación entre los } \\
\text { diferentes stakeholders. } \\
\text { V8: Aumenta la profesionalización de } \\
\text { la DMO. }\end{array}$ & $\begin{array}{l}\text { I1: Existe el riesgo de que las estrategias } \\
\text { se centren en el corto plazo, al } \\
\text { demandar el sector privado resultados } \\
\text { inmediatos. } \\
\text { I2: Mayor riesgo de discontinuidad en la } \\
\text { financiación. } \\
\text { I3: Su captación requiere un mayor } \\
\text { esfuerzo por parte de la DMO. } \\
\text { I4: Sectores de población ajenos a la } \\
\text { actividad turística pueden entender } \\
\text { la financiación privada como una } \\
\text { interferencia de intereses privados en } \\
\text { la política de la ciudad. } \\
\text { I5: Requiere de mecanismos de control } \\
\text { para evitar que "unos pocos" } \\
\text { controlen la DMO y gestión turística } \\
\text { del destino. }\end{array}$ \\
\hline
\end{tabular}




\begin{tabular}{|c|c|c|}
\hline & Ventajas & Inconvenientes \\
\hline $\begin{array}{c}\text { Recursos } \\
\text { autogenerados }\end{array}$ & $\begin{array}{l}\text { V1: Su obtención se entiende como un } \\
\text { factor de éxito en su gestión, lo que } \\
\text { conlleva a una mayor implicación } \\
\text { del sector público y privado } \\
\text { V2: Su obtención requiere una } \\
\text { orientación comercial. } \\
\text { V3: Supone un "feedback" importante } \\
\text { e inmediato de consumidores y } \\
\text { usuarios. } \\
\text { V4: Lleva a la DMO a desvincularse de } \\
\text { actitudes menos dinámicas, propias } \\
\text { de estructuras más burocratizadas. } \\
\text { V5: La DMO se convierte en un centro } \\
\text { de venta de productos y prestación } \\
\text { de servicios turísticos, dándole } \\
\text { estabilidad. } \\
\text { V6: Obliga a desarrollar una estrategia } \\
\text { empresarial, mejorando } \\
\text { competitividad de la DMO. } \\
\text { V7: Reduce la dependencia de fondos } \\
\text { públicos de la DMO. }\end{array}$ & $\begin{array}{l}\text { I1: Peligro de centrarse en el éxito a corto } \\
\text { plazo y dejar en un segundo plano } \\
\text { objetivos principales de la gestión } \\
\text { turística a medio y largo plazo. } \\
\text { I2: Algunas actividades pueden ser } \\
\text { vistas por los empresarios como } \\
\text { competencia directa, e incluso desleal } \\
\text { (reservas hoteleras, de la venta de } \\
\text { productos, reserva de actividades, } \\
\text { etc.) } \\
\text { I3: Hay que buscar mecanismos de } \\
\text { consenso con los empresarios, para } \\
\text { evitar conflictos de competencia. } \\
\text { I4: Que el objetivo se centre en la } \\
\text { obtención de más ingresos y mayores } \\
\text { beneficios, dejando en un segundo } \\
\text { plano los verdaderos objetivos de la } \\
\text { DMO. }\end{array}$ \\
\hline
\end{tabular}

Fuente: Elaboración propia a partir de DMAI (2015), ETB y TMI (2003), FEMP (2008), Ramió (2009), Ruiz (2010) y UNWTO (2008).

\section{METODOLOGÍA}

Hedrick-Wong y Choong (2017) establecen diversos rankings de las ciudades más importantes del mundo en materia de turismo en 2016, en función de diferentes parámetros: número de visitantes con pernoctación, volumen de gasto turístico, crecimiento interanual del turismo, etc. Estos autores elaboran un listado denominado Top 100 ciudades-destino, en el que aparecen las cien ciudades más visitadas del mundo, en función del número de visitantes que pernoctan en el destino. El trabajo de investigación que aquí se desarrolla se centra en las treinta y cinco primeras ciudades de ese ranking (Cuadro3).

El listado está encabezado por Bangkok, que en 2016 recibió 21,47 millones de visitantes, que gastaron 14,84 millones de USD, y finaliza con Sidney, en la 35 a posición, con un total de 3,75 millones de visitantes y unos ingresos por gasto de los turistas de 6,40 millones de dólares (Hedrick-Wong y Choong, 2017).

De estas treinta y cinco mejores ciudades-destino, nuestro estudio se centra en analizar aquellas que disponen de una DMO de carácter público-privado, que se encargue de la gestión o promoción del destino ${ }^{1}$. Estas se han identificado a través de las páginas web

1 Es cierto que hasta ahora se han diferenciado las entidades de gestión turística (DMO) de las entidades de promoción turística (DMkO). Sin embargo, al realizar este estudio todas las entidades analizadas se autodenominan "DMO" sin hacer diferencias en cuanto a la gestión/promoción. Por ello, a partir de ahora, todas las entidades analizadas en nuestro trabajo serán denominadas DMO y, más adelante, se analizará si realmente gestionan el turismo en el destino o no. 
oficiales del destino. Por tanto, el Cuadro 4 resume los destinos objeto de estudio, así como las DMO de la gestión /marketing del destino.

\section{Cuadro 3}

TOP 35 CIUDADES-DESTINO MÁS IMPORTANTES DEL MUNDO Y SU FORMA DE GESTIÓN/MARKETING

\begin{tabular}{|c|c|c|c|c|c|}
\hline RANK. & CIUDAD & GESTIÓN/ MARKETING & RANK. & CIUDAD & $\begin{array}{l}\text { GESTIÓN/ } \\
\text { MARKETING }\end{array}$ \\
\hline 1 & Bangkok & Gobierno & 19 & Shanghái & Gobierno \\
\hline 2 & Londres & $\mathrm{CPP}$ & 20 & Praga & Gobierno \\
\hline 3 & París & $\mathrm{CPP}$ & 21 & Los Ángeles & $\mathrm{CPP}$ \\
\hline 4 & Dubái & Gobierno & 22 & Madrid & Gobierno \\
\hline 5 & Nueva york & $\mathrm{CPP}$ & 23 & Múnich & Gobierno \\
\hline 6 & Singapur & Gobierno & 24 & Miami & $\mathrm{CPP}$ \\
\hline 7 & Kuala Lumpur & Gobierno & 25 & Dublín & Gobierno \\
\hline 8 & Estambul & $\mathrm{CPP}$ & 26 & Berlín & CPP \\
\hline 9 & Tokio & $\mathrm{CPP}$ & 27 & Mumbai & Gobierno \\
\hline 10 & Seúl & Gobierno & 28 & Ryad & Gobierno \\
\hline 11 & Hong Kong & Gobierno & 29 & Toronto & $\mathrm{CPP}$ \\
\hline 12 & Barcelona & $\mathrm{CPP}$ & 30 & Chennai & Gobierno \\
\hline 13 & Ámsterdam & $\mathrm{CPP}$ & 31 & Pekín & Gobierno \\
\hline 14 & Milán & Gobierno & 32 & Lima & Gobierno \\
\hline 15 & Taipéi & Gobierno & 33 & San Francisco & $\mathrm{CPP}$ \\
\hline 16 & Roma & Gobierno & 34 & Vancouver & $\mathrm{CPP}$ \\
\hline 17 & Osaka & CPP & 35 & Sídney & Gobierno \\
\hline 18 & Viena & Gobierno & & & \\
\hline
\end{tabular}

*Colaboración público-privada (CPP).

Fuente: Elaboración propia a partir de Hedrick-Wong y Choong (2017).

Para la realización del estudio, se elaboró un cuestionario que se envió a los directores o responsables de la financiación de estas entidades. La redacción del cuestionario se elaboró en función de la revisión bibliográfica realizada, la cual permitió identificar una 
serie de ventajas y desventajas de las diferentes fuentes de financiación que la literatura científica asume como ciertas.

\section{Cuadro 4}

\section{DMO DE LAS 35 CIUDADES-DESTINO MÁS IMPORTANTES DEL MUNDO}

\begin{tabular}{|l|l|}
\hline CIUDAD & ENTIDAD \\
\hline Londres & London and partners \\
\hline París & The Paris Convention and Visitors Bureau \\
\hline Nueva York & New York and Company \\
\hline Estambul & The Istanbul Convention \& Visitors Bureau \\
\hline Tokio & Tokyo Convention \&Visitors Bureau \\
\hline Barcelona & Barcelona Turisme \\
\hline Ámsterdam & Amsterdam Marketing \\
\hline Osaka & Osaka Convention \&Tourism Bureau \\
\hline Los Ángeles & Los Angeles Tourism \& Convention Board \\
\hline Miami & Greater Miami Convention \& Visitors Bureau \\
\hline Berlín & Visit Berlin \\
\hline Toronto & Tourism Toronto \\
\hline San Francisco & San Francisco Travel Association \\
\hline Vancouver & Tourism Vancouver \\
\hline
\end{tabular}

Fuente. Elaboración propia.

La población objeto de estudio estaba formada por catorce entidades a encuestar, de las cuales se consiguió la participación de ocho $(57,14 \%)$, cuyas respuestas fueron de la calidad y cantidad suficientes, además de mostrar una gran homogeneidad, con unos resultados obtenidos fiables y significativos. El envío de correos electrónicos con el cuestionario se realizó en varias fases, ya que fue necesario repetir su envío varias veces a la mayoría de los encuestados para motivar su participación (Cuadro 5).

No se consiguió la tasa de participación esperada. De hecho, de las catorce entidades a las que se le envió el cuestionario el 21,42\% decidió no participar en el estudio, esgrimiendo el motivo de que quebrantaba su política de protección de datos. La información relacionada con la financiación, representada en el Figura 2, de aquellas que no contestaron el cuestionario, se obtuvo mediante el estudio de la información y los informes disponibles en sus páginas web, así como del análisis de fuentes secundarias, de manera que se trabajó con datos del 78,52\% de las DMO seleccionadas. 


\section{Cuadro 5 \\ FICHA TÉCNICA DEL CUESTIONARIO}

\begin{tabular}{|l|l|}
\hline ÁMBITO DE ESTUDIO & $\begin{array}{l}\text { Entidades público-privadas de gestión/marketing de los } 35 \text { mejores } \\
\text { destinos del mundo }\end{array}$ \\
\hline TAMAÑO MUESTRAL & 14 \\
\hline GRADO DE RESPUESTA & $8(57,14 \%)$ \\
\hline FECHA DE TRABAJO & Octubre - Noviembre de 2017 \\
\hline TIPO DE ESTUDIO & Cuestionario estructurado por correo electrónico \\
\hline
\end{tabular}

Fuente: Elaboración propia.

Para obtener la información necesaria, se han utilizado distintos tipos de preguntas, que se pueden clasificar en función de dos criterios (Fernández, 2000): según el formato de la respuesta y según la información facilitada. Según el tipo de respuesta, el cuestionario incluye preguntas abiertas, cerradas y mixtas. Dentro del segundo tipo, se han incluido preguntas dicotómicas y multicotómicas, éstas últimas, tanto de respuesta única como múltiple.

Las escalas empleadas para la medición de las variables de estudio han sido también de diferentes tipos. Se han empleado escalas no métricas de carácter nominal, para identificar las categorías u opciones con las que se identifica la opinión del entrevistado, en el caso del análisis de variables cualitativas que carecen de significado cuantitativo. Además, se ha utilizado una escala de medición de actitudes de tipo Likert (puntuada correlativamente de 1 a 5 , según el interés en la opinión del encuestado), que facilitaba al encuestado valorar las diferentes afirmaciones planteadas.

Finalmente, el cuestionario se estructuró de acuerdo con los siguientes bloques de preguntas:

1. Importancia de la gestión público-privada de los destinos.

2. Evaluación de las ventajas e inconvenientes de cada fuente de financiación.

3. Evaluación del papel de cada fuente de financiación en la estructura financiera de una DMO.

\section{RESULTADOS}

Antes de comenzar con la descripción de los resultados obtenidos en el cuestionario, es importante conocer qué proporción de las treinta y cinco ciudades-destino más importantes del mundo cuentan con DMO público-privadas y cómo se estructuran, organizan $\mathrm{y}$ financian.

Así, solo catorce de las treinta y cinco ciudades más visitadas del mundo (Figura 1) disponen de una DMO para la gestión y/o promoción del turismo en el destino. 


\section{Figura 1 \\ TIPO DE ENTIDAD DE GESTIÓN/MARKETING TURÍSTICO}

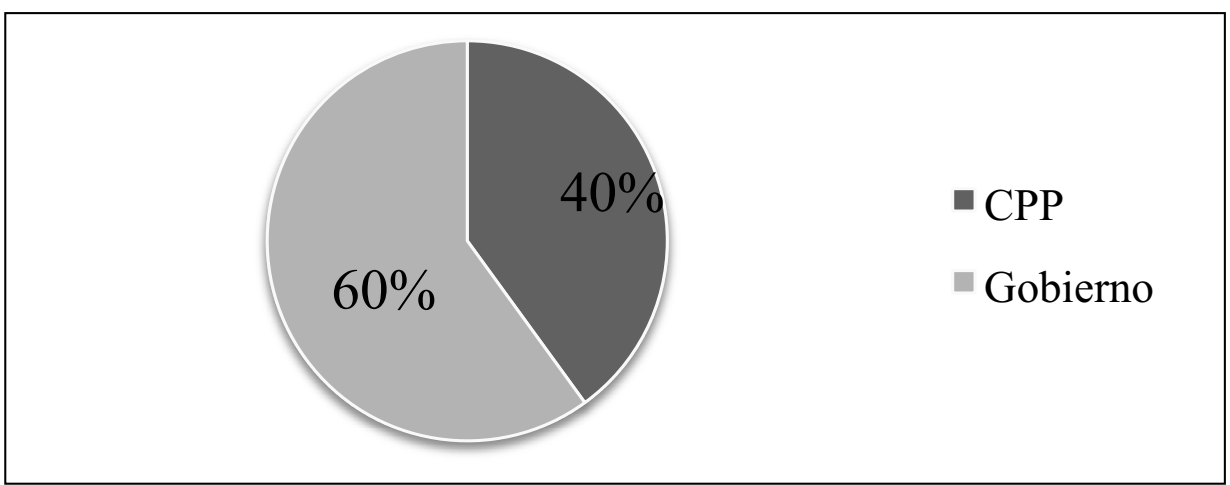

Fuente: Elaboración propia.

Todas, a excepción de una que tiene forma de consorcio mixto, son sociedades sin ánimo de lucro. Respecto a la estructura organizativa, todas, a excepción de una que sigue un modelo matricial, se organizan bajo una estructura clásica lineal, basada en el principio de jerarquía y en el mantenimiento de la unidad de mando.

En lo referente a su estructura financiera (Figura 2), la financiación pública $(48,80 \%)$ es la base del presupuesto de las DMO, que de media es de 27,5 millones de euros. El resto de la financiación se reparte entre la financiación privada $(28,81 \%)$ y los recursos autogenerados $(22,38 \%)$.

Figura 2

ESTRUCTURA FINANCIERA DE LAS DMO

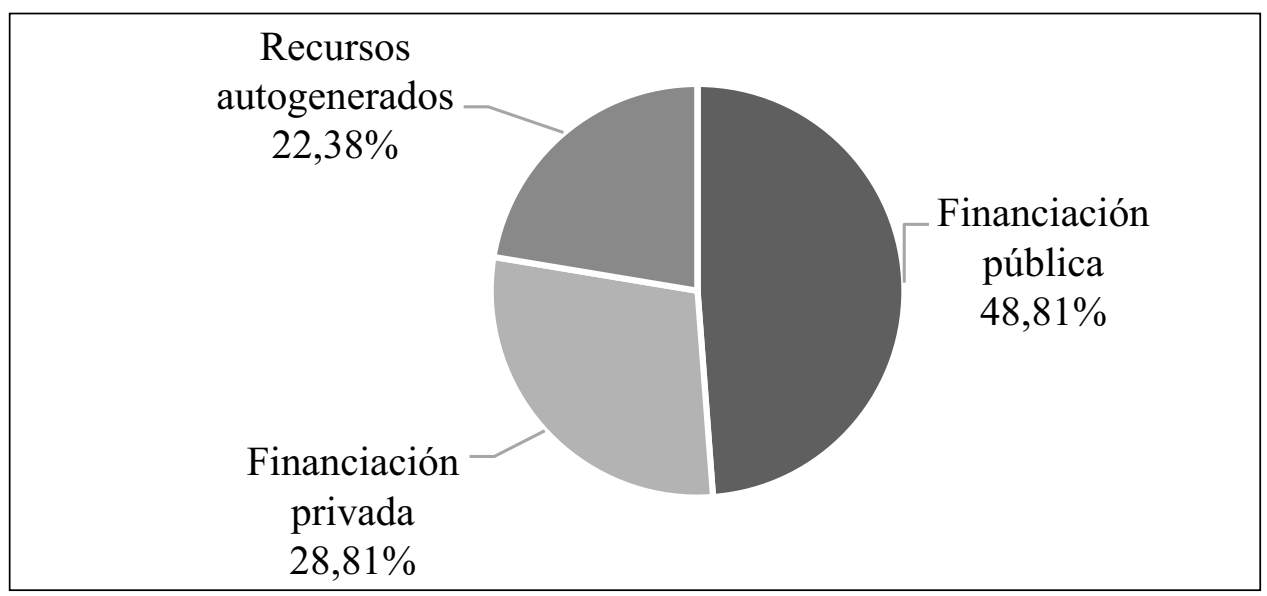

Fuente: Elaboración propia. 
A continuación comienza el bloque en el que se analiza la opinión de las DMOs acerca de diferentes cuestiones relacionadas con la organización y financiación de las entidades de gestión del turismo.

En primer lugar se pretendía conocer la opinión de las DMO sobre la importancia de una gestión público-privada de un destino turístico para su competitividad. Puede observarse (Figura 3) queconsideran la gestión público-privada como importante, con un valor medio de 4 sobre cinco. Ninguna DMO entiende que esta forma de gestión del turismo no es importante para el desarrollo turístico competitivo del destino.

Por tanto, parece que las entidades de gestión encuestadas tienen asumida la importancia y el papel fundamental de la participación integrada, coordinada y conjunta de los actores públicos y privados para una gestión eficiente del destino.

\section{Figura 3 \\ IMPORTANCIA DE UNA GESTIÓN PÚBLICO-PRIVADA DE UN DESTINO TURÍSTICO PARA SU COMPETITIVIDAD}

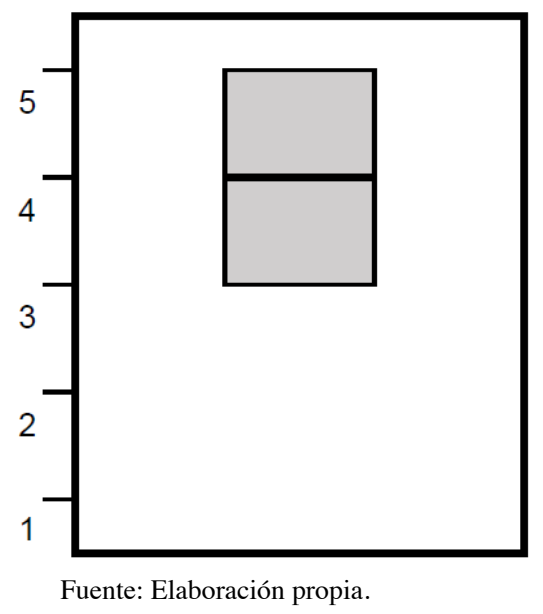

A continuación, se procedió a evaluar el grado de acuerdo de las DMOs con las ventajas e inconvenientes para el origen de las fuentes de financiación de las entidades de gestión, que se identificaron en el marco teórico, resumidas en la Tabla 2.Respecto a las ventajas asociadas a la financiación de origen público, tal y como refleja el Figura4, no existe un alto grado de acuerdo en torno a ellas. Las DMOs están algo a favor (con una mediana de 3,5 sobre 5) de que la financiación pública facilita la implicación del sector público en el desarrollo de la política turística de su entorno (V1) y de que favorece la transparencia en cuanto al destino de los fondos, al estar sujetos a las normas de la contabilidad y transparencia pública (V2). Sin embargo, no comparten que implique la igualdad de todas las empresas interesadas en la participación en la gestión turística (V3), ni que suponga una mayor estabilidad de la DMO a medio-largo plazo (V4), puntuando la mitad de los encuestados estas afirmaciones como en desacuerdo o totalmente en desacuerdo. 


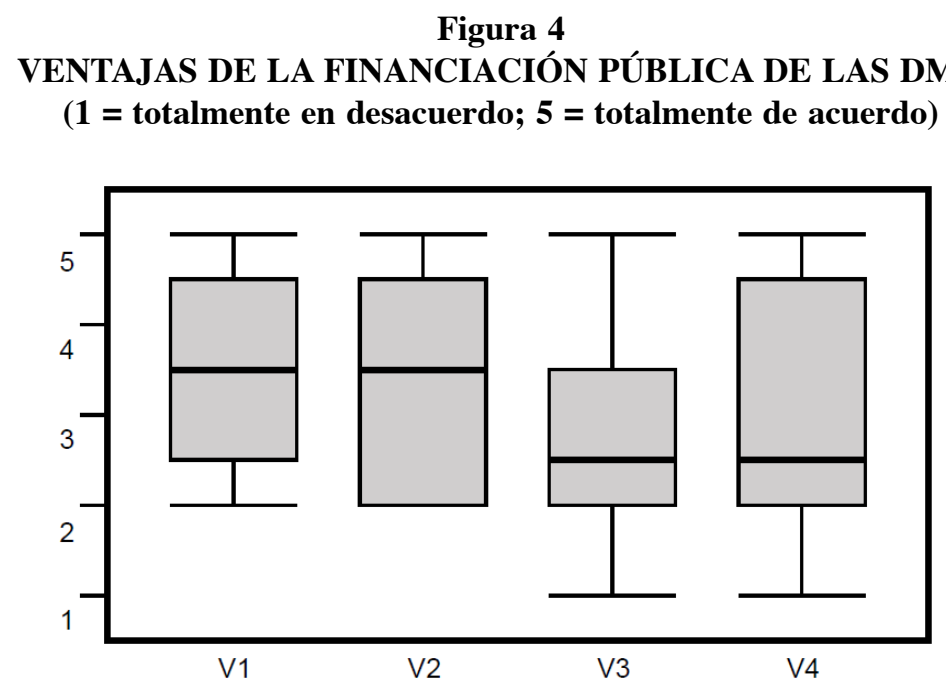

Fuente: Elaboración propia.

En lo que se refiere a los inconvenientes (Figura5) de la financiación pública, destaca que las DMO solo están de acuerdo con que implica una mayor influencia de los poderes públicos en la toma de decisiones de la DMO (I6).Entienden que la financiación pública no supone una menor rapidez de respuesta de las DMO a las necesidades del mercado global (I1), ni que genere recelos en la población (I3) y que no entorpece a que el sector público y privado trabajen en un mismo sentido (I4).

Figura 5

INCONVENIENTES DE LA FINANCIACIÓN PÚBLICA DE LAS DMO

$(1$ = totalmente en desacuerdo; 5 = totalmente de acuerdo $)$

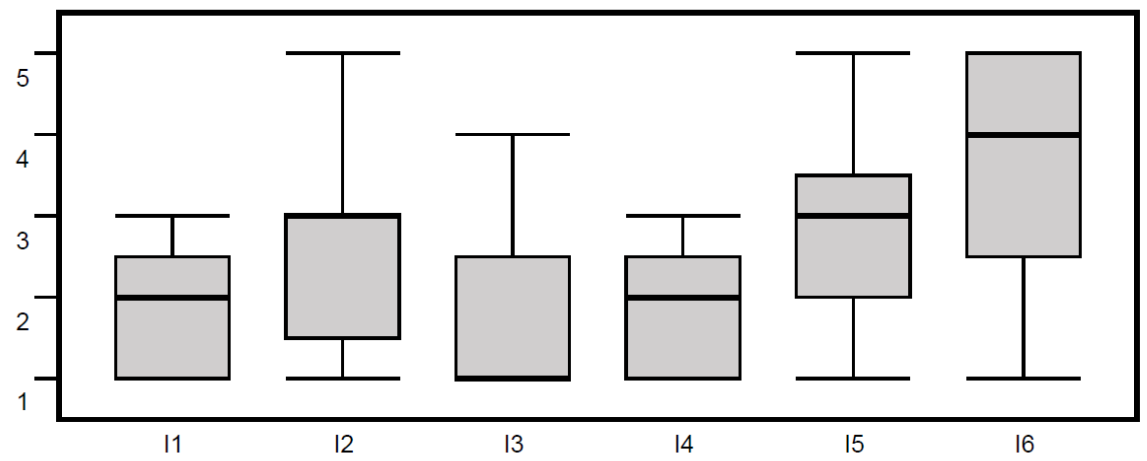

Fuente: Elaboración propia. 
Además, es importante conocer el papel que debe otorgarse a la financiación pública. Así, tal y como muestra el Figura 5, no existe un acuerdo total en este sentido, ya que la mediana adopta valores neutrales en ambos casos. Si bien es cierto, un mayor número de DMO están totalmente de acuerdo con que suponga la fuente principal.

\section{Figura 6 \\ PAPEL DE LA FINANCIACIÓN PÚBLICA EN LA ESTRUCTURA FINANCIERA DE UNA DMO \\ ( 1 = totalmente en desacuerdo; 5 = totalmente de acuerdo)}

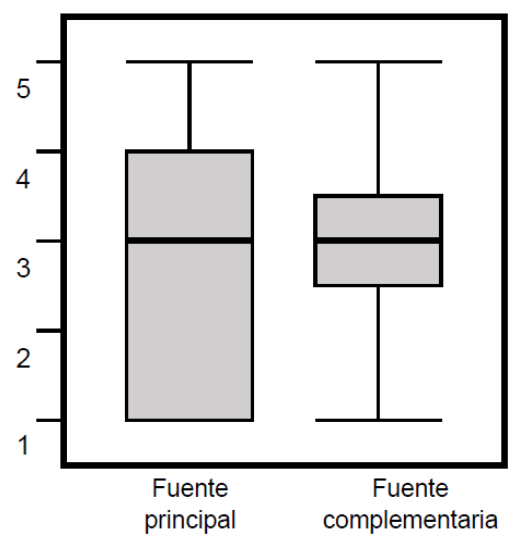

Fuente: Elaboración propia.

Las denominadas "tasas al turismo" son una fuente de financiación de carácter público que se emplean para financiar la gestión del turismo en un destino, dotando de más medios y oportunidades a los gestores (Rodríguez, 2009; Ruiz y Guía, 2004).

El tipo de tasa más común y empleado es el llamado "impuesto al alojamiento", que acaba afectando al volumen de llegadas e ingresos por turismo (Aguiló et al., 2005), Sin embargo, hay corrientes que no lo consideran una buena opción, afirmando que lo que se necesita es un cambio en el modelo de financiación y el establecimiento de una tasa no soluciona el problema (Izard et al., 2010; Kerr et al., 2001; Pechlaner y Tschurtschenthaler, 2003).

Se aprovechó para conocer la opinión entorno a estas tasas turísticas y, como muestra el Figura6, las DMO no consideran que favorezcan un turismo sostenible y de calidad, ni que dañen el turismo en el destino. Consideran que todo depende de la gestión que realice en este sentido, añadiendo que la tasa al alojamiento y los procesos de gobernanza relacionados, a menudo, están sujetos a la interferencia política y la vulnerabilidad. Sin embargo, en los principales destinos urbanos con importante volumen de visitantes de fuera de la ciudad, este sistema impositivo es eficiente y una forma de "autoliquidación" pagada por no residentes. 
Todas las DMO encuestadas, a excepción de dos, consideran la tasa al alojamiento como la más adecuada para el desarrollo sostenible del turismo en su ciudad. Una de ellas aboga por establecer tasas que graben a las empresas hoteleras directamente, por los ingresos fruto del alquiler de habitaciones. De este modo, el cliente no es el último pagador sino el hotel, aunque puede que el empresario acabe trasladando la carga al precio por habitación. Otra entiende que una tasa aplicada a los billetes de avión sería lo idóneo para su ciudad.

FIGURA 6

\section{LAS TASAS AL TURISMO FAVORECEN A UN TURISMO SOSTENIBLE DE CALIDAD Y SI NO BENEFICIAN AL TURISMO EN LA CIUDAD $(1$ = totalmente en desacuerdo; 5 = totalmente de acuerdo)}

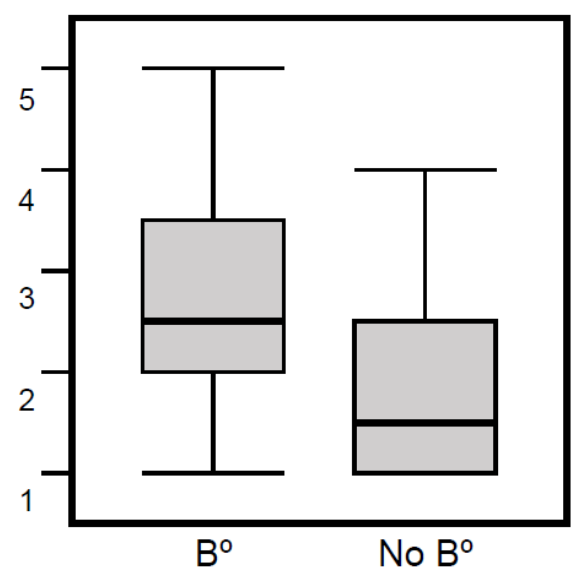

Fuente: Elaboración propia.

Con respecto a las fuentes de financiación de origen privado, se identificaron ocho ventajas (Tabla 5), de las que con cuatro de ellas están de acuerdo las DMO. Tal y como refleja el Figura 7, estas consideran que la financiación de las DMO a través de fondos privados es un estímulo para que sean más eficaces en el logro de sus objetivos y fomentar la participación del sector privado (V1), para que sector público y privado trabajen en la misma dirección (V3) y para la profesionalización de las DMO (V8).

Las DMO tienen claro que financiar su presupuesto con fondos de origen privado reduce la dependencia de fondos públicos (V6), valorando, todas, el grado de acuerdo con una puntación de 4 o 5 . Sin embargo, no tienen muy claro que reduzca la influencia de la política en la gestión del destino o de la DMO.

Respecto a los inconvenientes de la financiación privada (Figura 8), la mayoría de las DMO mantienen una posición neutral, destacando un poco el grado de acuerdo con que este tipo de financiación requiere un mayor esfuerzo su captación (I3).

Sí que están en desacuerdo en parte con que exista un mayor riesgo de discontinuidad en la financiación (I2) y con que suponga una interferencia de intereses privados en la política de la ciudad (I4), arrojando ambos inconvenientes medias por debajo de 3 . 
Figura 7

VENTAJAS DE LA FINANCIACIÓN PRIVADA DE LAS DMO

( 1 = totalmente en desacuerdo; 5 = totalmente de acuerdo)

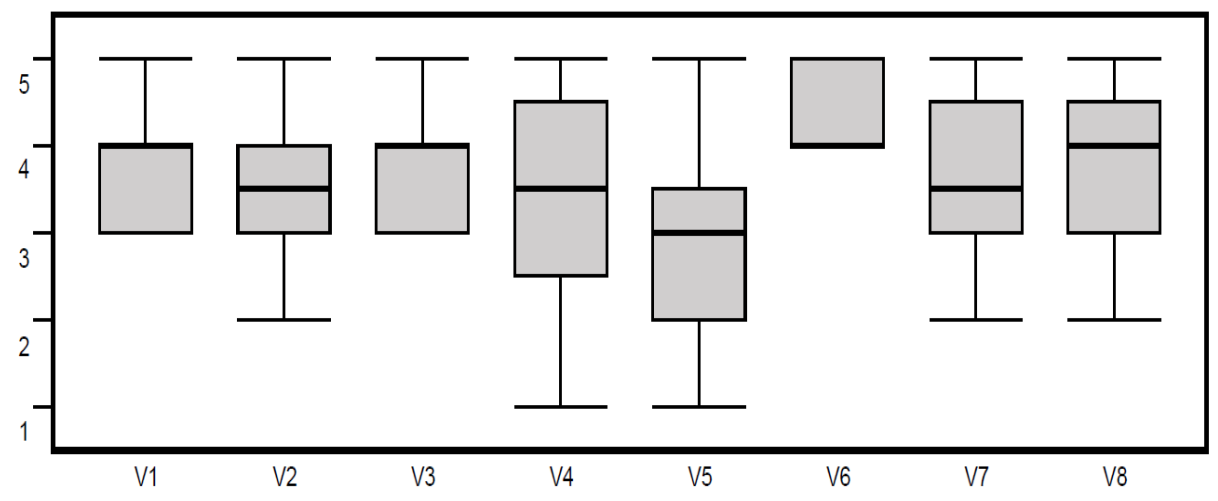

Fuente: Elaboración propia.

Figura 8

INCONVENIENTES DE LA FINANCIACIÓN PRIVADA DE LAS DMO

( 1 = totalmente en desacuerdo; 5 = totalmente de acuerdo $)$

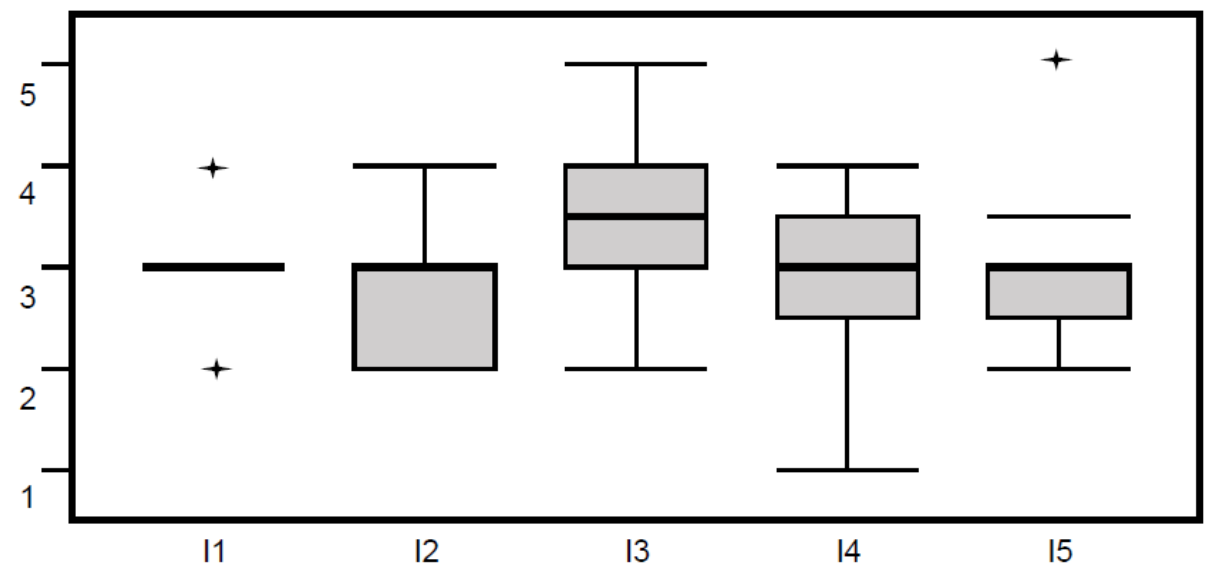

Fuente: Elaboración propia.

En lo que se refiere al papel de la financiación privada en la estructura financiera de una DMO, los encuestados se decantan por que éste sea de carácter complementario y no asuma un rol principal (Figura 9). 


\section{Figura 9 \\ PAPEL DE LA FINANCIACIÓN PRIVADA EN LA ESTRUCTURA \\ FINANCIERA DE UNA DMO \\ ( 1 = totalmente en desacuerdo; 5 = totalmente de acuerdo)}

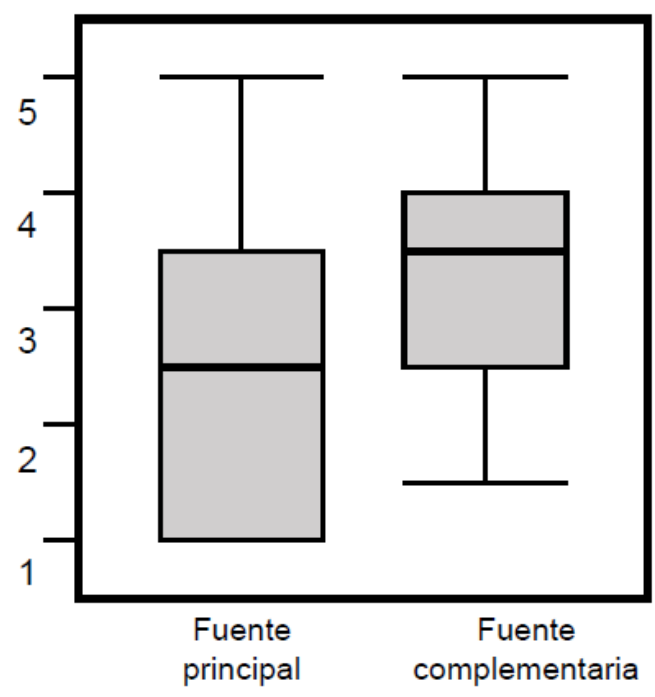

Fuente: Elaboración propia.

Por último, se analizaron las ventajas, inconvenientes y papel de los recursos autogenerados, los cuales tienen un elevado grado de aceptación tanto por la literatura científica (Arbogast et al., 2017; Beritelli y Laesser, 2014; Izard et al., 2010), como por la población en general (Rodríguez, 2009).

A la vista del Figura 10, no existe ninguna ventaja que destaque por un elevado grado de acuerdo por parte de las DMO. Si bien es cierto, puede observarse que las entidades están algo más de acuerdo, al concentrarse más volumen de puntuaciones entre 3 y 5 , con que los recursos autogenerados requieren una orientación comercial (V2), dotándola de más estabilidad (V5), son un "feedback" a tener en cuenta (V3) y reducen la dependencia del sector público (V7). Entienden, en parte, que su obtención supone un factor de éxito de su gestión (V1).

De nuevo, son los inconvenientes los que menor grado de acuerdo reflejan. No consideran que la financiación con recursos autogenerados implique que las DMO se centren en el éxito a corto plazo y dejen para un segundo plano los objetivos principales de la gestión turística a medio y largo plazo (I1). No obstante, están algo de acuerdo con que se busquen mecanismos de consenso entre los empresarios, para evitar conflictos de competencia (I3). 
Figura 10

VENTAJAS DE LA FINANCIACIÓN DE LAS DMO CON RECURSOS

AUTOGENERADOS

$(1$ = totalmente en desacuerdo; 5 = totalmente de acuerdo $)$

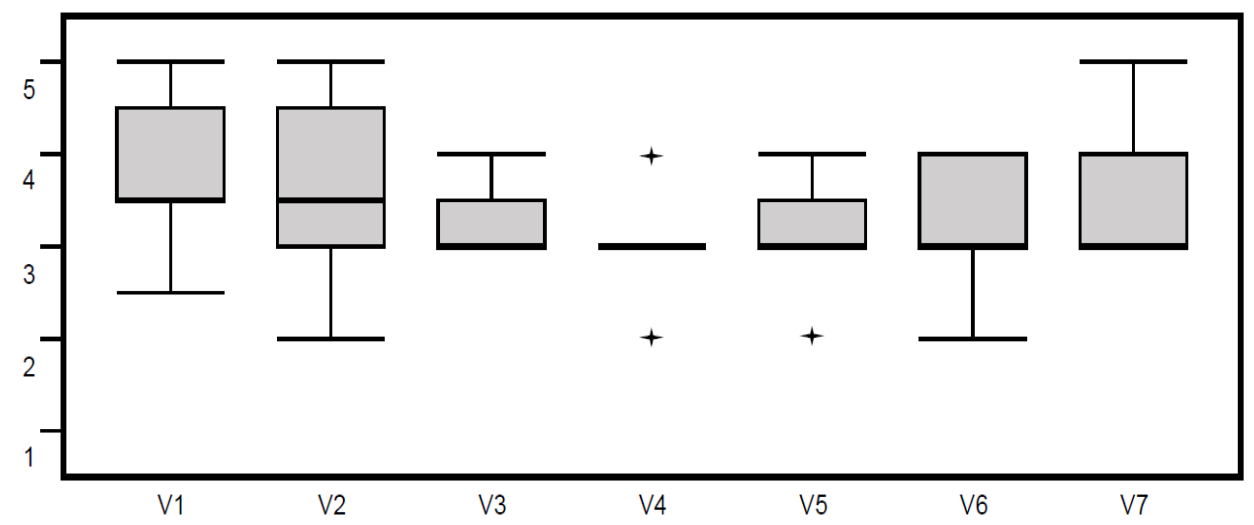

Fuente: Elaboración propia.

Figura 11

INCONVENIENTES DE LA FINANCIACIÓN DE LAS DMO CON RECURSOS

AUTOGENERADOS

$(1$ = totalmente en desacuerdo; 5 = totalmente de acuerdo $)$

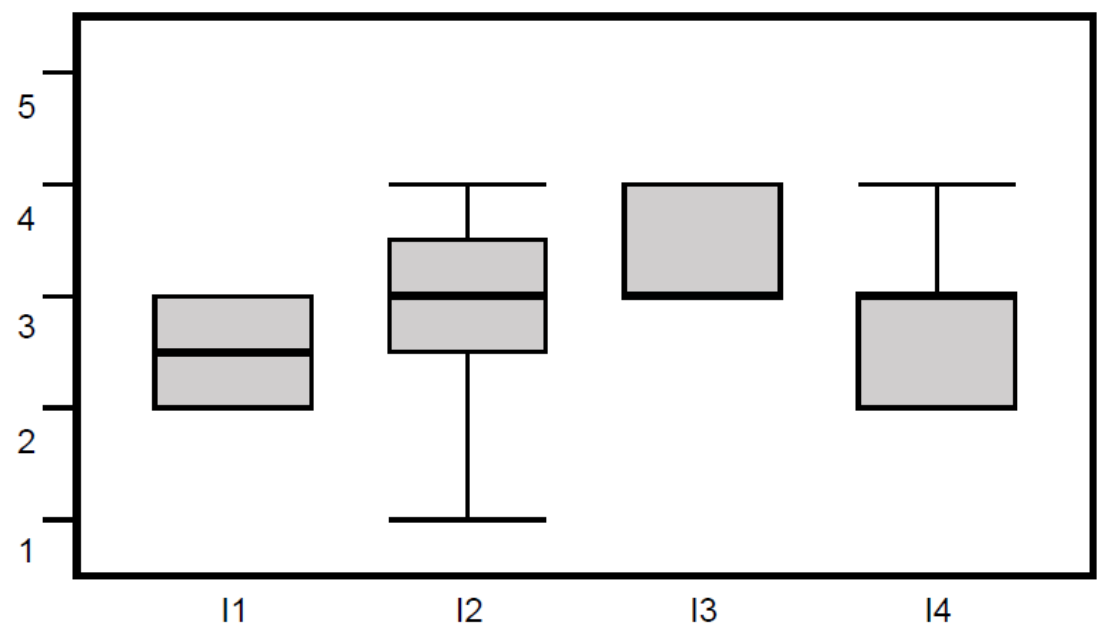

Fuente: Elaboración propia. 
Por último, la mediana del papel que deben asumir los recursos autogenerados en la financiación de las DMO se sitúa en 3, destacando mayor concentración de valoraciones por encima de la mediana en el caso de que deben asumir un papel complementario y no principal.

Figura 12

PAPEL DE LOS RECURSOS AUTOGENERADOS EN LA FINANCIACIÓN
DE UNA DMO

$(1$ = totalmente en desacuerdo; 5 = totalmente de acuerdo $)$

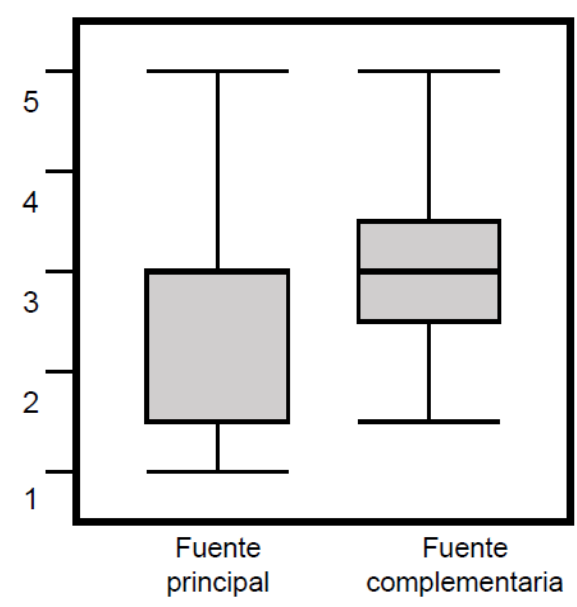

Fuente: Elaboración propia.

\section{CONCLUSIONES}

La gestión de los destinos turísticos debe garantizar el desarrollo sostenible y competitivo del turismo desde el entendimiento, la coordinación y el respeto de todos los agentes que forman parte y se ven afectados por la actividad turística. Las DMO público-privadas son consideradas como la fórmula de gestión más adecuada para el logro de este objetivo, debiendo gozar de autonomía financiera con respecto a los presupuestos públicos, de modo que superen los problemas de financiación a los que se enfrentan los destinos.

La literatura científica no establece una fórmula de estructura financiera ideal que deban mantener estas entidades. Sí que dispone que, en los destinos maduros y asentados, con sectores empresariales turísticos importantes, como es el caso de las ciudades más visitadas del mundo, aquí estudiado, sus entidades de gestión turística deben estar en manos de la gestión privada, en cuyos presupuestos, la financiación que no es de origen público debe ser proporcional a la importancia del sector privado en la economía del turismo del destino.

Pese a ello, la gestión del turismo a través de DMO público-privadas no es una cuestión extendida en las ciudades más visitadas del mundo, de manera que solo el $40 \%$ cuenta 
con una DMO, conformadas en su mayoría como sociedades sin ánimo de lucro con estructuras organizativas lineales de carácter clásico, las cuales deben evolucionar hacia estructuras organizativas más orientadas al mercado. Las entidades encuestadas, de hecho, consideran importante la gestión público privada de los destinos.

Las DMO analizadas son financieramente dependientes del sector público, quien aporta el $50 \%$ de sus recursos presupuestarios, siendo los recursos autogenerados la fuente de financiación menos importante, pese al papel fundamental que le otorga la literatura científica. Esta estructura financiera es consecuente con la opinión que han proporcionado las DMO, que abogan por una estructura en la que la financiación de origen público tenga un papel principal, y la privada y los recursos autogenerados asuman un papel complementario.

De hecho, las DMO no parecen compartir la opinión de la literatura especializada acerca de las ventajas e inconvenientes de las diferentes fuentes de financiación, mostrando desacuerdo y posiciones neutrales al valorarlas.

En cuanto a la financiación pública, solo reconoce uno de sus inconvenientes, rechazando que suponga menor rapidez de respuesta, que genera recelos en la población y que implique mayor estabilidad. Valoran el papel de la financiación privada como estímulo de eficacia y la profesionalización de las DMO, aunque no entienden que reduzca la influencia de la política en su gestión. Y, en relación a los recursos autogenerados, no consideran que implique que las DMO se centren en el éxito a corto plazo.

En general, entienden que la financiación privada y los recursos autogenerados deben suponer financiación complementaria a los fondos públicos.

Por tanto, queda validad la hipótesis de partida, ya que los resultados permiten afirmar que las DMO no tienen asumidas cuáles son las verdaderas ventajas e inconvenientes de mantener la estructura financiera que en la actualidad sostienen sus presupuestos, la cual podría ser más eficaz y eficiente si la adaptaran a las circunstancias de los destinos, teniendo en cuenta los efectos positivos y negativos de la financiación pública, privada y los recursos autogenerados, logrando así mayor autosuficiencia financiera y aliviando el problema de financiación al que se enfrenta la gestión de los destinos.

\section{BIBLIOGRAFÍA}

AGUILÓ, E., RIERA, A., y ROSSELLÓ, J. (2005): «The short-term price effect of a tourist tax through a dynamic demand model: The case of the Balearic Islands». Tourism Management, vol. 26 (3), pp. 359-365.

ARBOGAST, D., DENG, J., y MAUMBE, K. (2017): «DMO and Rural Tourism: A Stakeholder Analysis the Case of Tucker County, West Virginia». Sustainability, vol. 10, pp. 18-13.

ARCARONS, R., CAPELlÁ, S., GONZÁleZ, F., MIRALBELL, O., y PALLÁS, J. (2010): Gestión pública del turismo. Editorial UOC, Barcelona.

BERITELLI, P. y LAESSER, C. (2014): «Getting the cash-cow directors on board. An alternative view on financing DMO». Journal of Destination Marketing \& Management, vol. 2 (4), pp. 213-220. 
BIEDMA, J.M. (2010): «El Municipio Turístico andaluz: algunas consideraciones legales». Revista Andaluza de Derecho del Turismo, no 3, pp. 181-194.

BODLENDER, J A. (1982): «The Financing of Tourism Projects». Tourism Management, vol. 3, pp. 277-284.

BORNHORST, T., RITCHIE, J. B., y SHEEHAN, L. (2010): «Determinants of tourism success for DMO \& destinations: An empirical examination of stakeholders' perspectives». Tourism Management, vol. 31 (5), pp. 572-589.

CARRILLO-HIDALGO I., y PULIDO-FERNÁNDEZ J.I. (2019): «Examining the Organizational-Financial Structure of Public-Private Destination Management Organizations». En: Katsoni V., Segarra-Oña M. (Eds.) Smart Tourism as a Driver for Culture and Sustainability. Springer Proceedings in Business and Economics. Springer, Cham.

DAS, J. K. y GHOSH, S. (2014): «An analytical study on investment and financing scenario of tourism industry of west Bengal». Globsyn Management Journal, vol. 8 (1), pp. 39-52.

DMAI (Destination Marketing Association International) (2015): 2015 DMO Organizational \& Financial Profile Study. Consolidated Report. Destination Marketing Association International, Washington.

ETB (ENGLISH TOURISM BOARD) y TMI (TOURISM MANAGEMENT INSTITUTE) (2003): Destination Management Handbook. A sustainable approach. English Tourism Board y Tourism Management Institute, London.

FERNÁNDEZ, A. (2000): Investigación de mercados: obtención de información, $2^{\mathrm{a}}$ edición. Cívitas, Madrid.

FEMP, T. (2008): Modelos de gestión turística local: Principios y prácticas. Federación Española de Municipios y Provincias, Secretaría General de Turismo, Madrid.

FLUVIÀ, M., CARRERAS M., GARRIGA A. y RIGALL R. (2001): Las finanzas de los municipios turísticos catalanes. Departament d'economia de la UdG. Diputació de Girona.

GALÁN, S.C. (2014): «Participación y cooperación público-privada en el derecho del turismo». Papers de Turisme, $\mathrm{n}^{\mathrm{o}}$ 51, pp. 82-107.

HARA, T. (2013): «Reviewing Tourism Funding Model for Public Infrastructure and Destination Marketing Organizations: A Case of Orlando». Journal of Tourism Economics, Policy and Hospitality Management, vol. 1 (1), p. 3.

HENDRICK-WONG Y. y CHOONG D. (2017): Global Destination Cities Index. Mastercard, Nueva York.

IZARD, O.M., SIMÓN, R.A., HEREU, J.C., REVERTÉ, F.G., y PINEDA, J. M. P. (2010): Gestión pública del turismo, $\mathrm{n}^{\circ}$ 159.Editorial UOC, Barcelona.

HRISTOV, D. y ZEHRER, A. (2019). «Does distributed leadership have a place in destination management organisations? A policy-makers perspective». Current Issues in Tourism, vol. 22 (9), pp. 1.095-1.115.

KERR, B., BARRON, G. y WOOD, R.C. (2001): «Politics, Policy and Regional Tourism Administration: A Case Examination of Scottish Area Tourist Board Funding». Tourism Management, vol. 22, pp. 649-657. 
KNAFOU, R., (1991): «L'invention du lieu touristique: la passation d'un contrat et le surgissementsimultané d'un nouveau territoire ». Revue de Géographie Alpine, vol. 79 (4), pp. 11-19

KERIMOĞLU, E., y ÇIRACI, H. (2008): «Sustainable tourism development and a governance model for Frig Valley». ITU A/ Z, vol. 5 (2), pp. 22-43.

MANENTE, M. (2008): «Gestión de destinos y antecedentes económicos: definición y supervisión de destinos turísticos locales». En Definición y supervisión de destino turístico local. Conferencia Internacional de Turismo. Málaga. Disponible en https:// webunwto.s3.eu-west-1.amazonaws.com/imported_images/30058/manente_sp.pdf

MUÑOZ, A. y FUENTES, L. (2013): «La cooperación público privada en el ámbito de la promoción de los destinos. El análisis de redes sociales como propuesta metodológica». Cuadernos de Turismo, no 31, pp. 199-223.

PASTOR, V.J. y SOLER-DOMINGO, A. (2009):«Un análisis económico-presupuestario de los municipios turísticos en la Comunidad Valenciana». Gestión Turística, $\mathrm{n}^{\mathrm{o}}{ }^{12}$, pp. 141-163.

PECHLANER, H., y TSCHURTSCHENTHALER, P. (2003): «Tourism policy, tourism organisations and change management in Alpine regions and destinations: A European perspective». Current Issues in Tourism, vol.6 (6), pp. 508-539.

PIKE S. (2004): Destination Marketing Organizations. Elsevier, Oxford.

PIKE, S. (2007): Destination Marketing Organisations. Routledge, Abingdon.

PRESENZA A, SHEEHAN L, y RITCHIE JRB. (2005): «Towards a Model of the Roles and Activities of Destination Management Organizations». Journal of Hospitality, Tourism and Leisure Science, vol. 3 (1), pp. 1-16.

PULIDO-FERNÁNDEZ, J.I. (2010): «Las partes interesadas en la gestión turística de los parques naturales andaluces. Identificación de interrelaciones e intereses». Revista de Estudios Regionales, $\mathrm{n}^{\circ} 88$, pp. 147-175.

PULIDO-FERNÁNDEZ, M.C. (2014): Metodología para la implantación de la gobernanza como herramienta de gestión de destinos turísticos. Universidad de Jaén, Jaén.

RAMIÓ, C. (2009): La colaboración público-privada y la creación de valor público. Diputació de Barcelona, Colección Estudios, Serie Gobierno Local, (14).

REINHOLD, S., BERITELLI, P., y GRÜNIG, R. (2019). «A business model typology for destination management organizations». Tourism Review, vol. 74 (6): pp. 1.135-1.152. https://doi.org/10.1108/TR-03-2017-0065.

RODRÍGUEZ, D.R. (2009): «Mitigación de los impactos del turismo en espacios naturales protegidos y mejora de su financiación a través de medidas económicas. El caso de la Comunidad de Madrid». Boletín de la AGE, $\mathrm{n}^{\circ}$ 50, pp. 217- 238.

ROMÁN-MÁRQUEZ,A. (2011): «Planes de Dinamización y Excelencia Turística versus Municipios Turísticos: problemática, similitudes y diferencias esenciales». Papers de Turisme, n49-50, pp. 25-44.

RUBIO, J.I. (2002): «Gasto local y recursos tributarios». Tributos Locales, n ${ }^{\circ}$ 19, pp. 7-13.

RUÍZ, E. y GUÍA, J. (2004): «Financiación del municipio turístico y competitividad: estudio de los municipios turísticos de Cataluña». Papers de Turisme, $\mathrm{n}^{\circ}$ 35, pp. 59-75.

RUIZ, E. (2010): Estratègies de finançament dels municipis turístics i competitivitat: el cas dels municipis catalans. Universidad de Gerona, Gerona. 
SHEEHAN, L., RITCHIE, J.B., y HUDSON, S. (2007): «The destination promotion triad: Understanding asymmetric stakeholder interdependencies among the city, hotels, and DMO». Journal of Travel Research, vol. 6 (1), pp. 64-74.

SHEEHAN, L., VARGAS-SÁNCHEZ, A., PRESENZA, A., y ABBATE, T. (2016): «The use of intelligence in tourism destination management: An emerging role for DMO». International Journal of Tourism Research, vol. 18 (6), pp. 549-557.

UNWTO (ORGANIZACIÓN MUNDIAL DEL TURISMO) (2004): Survey of Destination Management Organisations Report. UNWTO, Madrid.

UNWTO (ORGANIZACIÓN MUNDIAL DEL TURISMO) (2008): Structures and Budgets of National Tourism Organizations (2004-2005). UNWTO, Madrid.

UNWTO (ORGANIZACIÓN MUNDIAL DEL TURISMO) (2017): Barómetro OMT del turismo mundial. Abril 2018. Vol. 16. UNWTO, Madrid.

VOLTES-DORTA, A., JIMÉNEZ, J.L., y SUÁREZ-ALEMÁN, A. (2014): «An initial investigation into the impact of tourism on local budgets: A comparative analysis of Spanish municipalities». Tourism Management, vol. 45, pp. 124-133. 